\title{
A RARE CASE REPORT DUCT CELL CARCINOMA OF PAROTID GLAND
}

\author{
Shiv Kumar' Imran Khan², Rajashree Bhati ${ }^{3}$, Bhupendra Saini ${ }^{4}$
}

1 Professor \& HOD, Department of Otorhinology, Government Medical College, Kota. ${ }^{2} 3^{\text {rd }}$ Year Resident, Department of Otorhinology, Government Medical College, Kota. 3 Associate Professor, Department of Pathology, Government Medical College, Kota. 43rd Year Resident, Department of Otorhinology, Government Medical College, Kota.

\section{ABSTRACT}

Salivary duct carcinoma is a rare malignant tumour of parotid gland. Patients are usually elderly men with a mean age ranging between 55 to 62 years. Till date around 200 cases have been reported in literature. In this paper, we report case of a 50-year-old male with salivary duct carcinoma of left parotid gland with left facial nerve palsy. The diagnosis was confirmed by aspiration cytology and histologically the tumour shows invasion in surrounding tissue and comedonecrosis along with hyalinization. Total left parotidectomy with excision of the adjacent facial nerve was performed. There were no recurrence or metastasis within 6 months of follow-up.

\section{KEYWORDS}

Infiltrative, Duct Cell Carcinoma of Parotid Gland.

HOW TO CITE THIS ARTICLE: Kumar S, Khan I, Bhati R, et al. A rare case report duct cell carcinoma of parotid gland. J. Evolution Med. Dent. Sci. 2016;5(53):3573-3574, DOI: 10.14260/jemds/2016/823

\section{INTRODUCTION}

Salivary duct carcinoma represents a rare and aggressive tumour with an estimated incidence of 1-3\% of all malignant salivary gland tumours. Salivary duct carcinoma commonly arises from the parotid gland and first described by Kleinsasser et al in $1968 . .^{1}$ and clinically present as a rapidly growing mass infiltrating the facial nerve. A number of patients have cervical lymphadenopathy at the time of diagnosis. ${ }^{2,3}$

\section{CASE REPORT}

A 50-year-old male reported to our Department of Otorhinolaryngology of Govt. Medical College, Kota, with a one year h/o of painless swelling in left parotid region with progressive facial paralysis. Physical examination showed a swelling of the left parotid gland which was painless on palpation, hard and non-compressible. There was no cervical lymphadenopathy and no abnormalities within the oral cavity. The CT scan examination of the neck showed heterogeneously enhancing soft tissue density mass in left parotid region with multiple calcific foci and obliterated overlying cutaneoussubcutaneous surface. Lesion abutting postero-lateral fibre of masseter, underlying bone normal. TNM staging of disease was T4aN0M0. Chest X-ray was normal. A total left parotidectomy with excision of the adjacent facial nerve and left neck lymph node dissection was performed and skin defect was sutured in layers. On gross examination, we received a hard $4 \times 3 \times 2 \mathrm{~cm}$, well circumscribed greyish yellow which was lobular and encapsulated. Microscopic examination showed ductal lesions showing invasion in surrounding tissue and comedo necrosis along with hyalinization.

There were no recurrences or metastases within 6 months of follow-up confirmed by CT neck.

Financial or Other, Competing Interest: None.

Submission 10-05-2016, Peer Review 09-06-2016,

Acceptance 15-06-2016, Published 04-07-2016.

Corresponding Author:

Dr. Imran Khan

Nearby Zama Masjid,

Udpura Morak Station

Kota,

E-mail: drimrankhan83@gmail.com

DOI: $10.14260 /$ jemds $/ 2016 / 823$

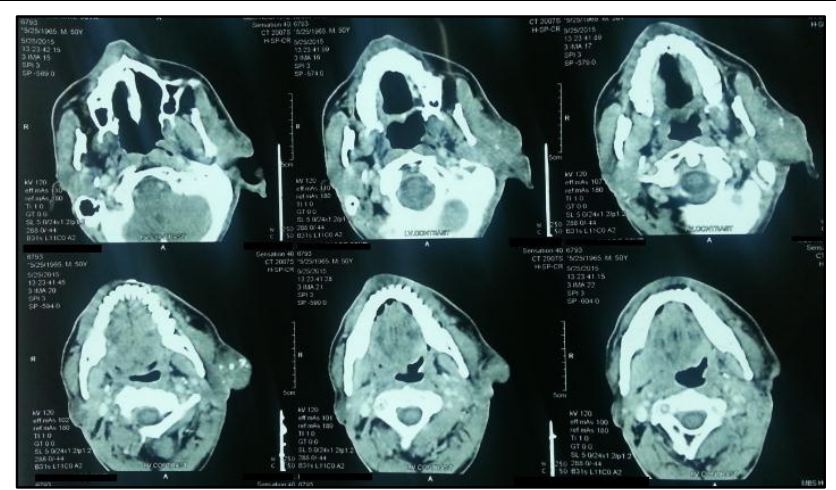

Fig. 1: Represents the CT of the PT with SDC from Left Parotid Gland Infiltrating the Deep Lobe

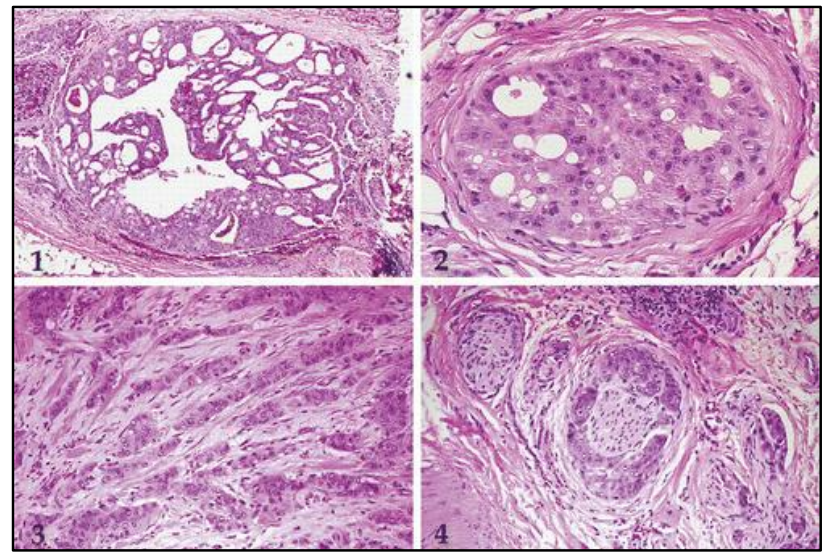

Fig. 2: Salivary Duct Cell Slide

\section{DISCUSSION}

Salivary duct carcinoma represents a rare and aggressive tumour with an estimated incidence of $1-3 \%$ of all malignant salivary gland tumors. ${ }^{4,5}$ Salivary duct carcinoma commonly arises from the parotid gland and clinically present as a rapidly growing mass infiltrating the facial nerve. Most treated patients with salivary duct carcinoma present with early locoregional recurrence with high propensity for distant metastases to the lung, bone and liver. ${ }^{6}$ 
Seventy percent of the patients with salivary duct carcinoma die of their disease within 3 years of diagnosis due to widespread metastases. ${ }^{7}$

Histopathologically salivary duct carcinoma bears a striking similarity to ductal carcinoma of the breast and is composed of intraductal and invasive components. Similar to the breast carcinoma, the intra-ductal component may appear as a cribriform, papillary or solid growth pattern, often with comedo-like central necrosis. The invasive carcinoma consists of irregular glands and cords of cells that frequently elicit a prominent desmoplastic reaction. Salivary duct carcinoma can occur de novo or as the malignant component of carcinoma expleomorphic adenoma. Most pathologists stress on the presence of flat sheets of tumour cells with cribriform patterns as characteristic feature of salivary duct carcinoma.

Delgado et al based on the degree of intraductal or infiltrative component have classified salivary duct carcinoma into 3 subtypes:

1. Predominantly intraductal, where $90 \%$ of the tumour is intraductal

2. Predominantly infiltrative, when less than $20 \%$ of the tumour is intraductal, or

3. Infiltrative, when the tumour is entirely infiltrative. The significance of this classification is not known, but it has been seen that the predominantly infiltrative tumour has dismal prognosis. Salivary duct carcinoma.

Several variants of salivary duct carcinoma such as sarcomatoid variant, low grade or mucin rich salivary duct carcinoma have been described. Literature reviews on the sarcomatous variant of salivary duct carcinoma, salivary duct carcinoma have been reported in only sixteen patients till date.

Sarcomatoid salivary duct carcinoma is characterized histologically by a biphasic neoplasm with carcinomatous and sarcomatoid elements.

Due to the rarity of this malignancy, no consistent therapeutic concept and protocol exists for this tumour entity. Majority treat patients with salivary duct carcinoma with a radical surgical approach and adjuvant external radiotherapy, whereas others recommend adjuvant therapy based on the pathological stage, grade, margin and perineural invasion. Recurrence was seen in all the patients reported in literature with parotid salivary duct carcinoma who have undergone parotidectomy and did not undergo lymph nodal neck dissection.

In the present case, patient has been treated with a total left parotidectomy with excision of the adjacent facial nerve and left neck lymph node dissection was performed and skin defect was sutured in layers and adjuvant radiotherapy. In this case, locally advanced salivary duct carcinoma patients have survived disease free even 6 months after completion of treatment. Thereby, we stress the fact that oncological cure in patients with salivary duct carcinoma can still be achieved with the radical surgical approach and adjuvant radiotherapy. Overall, 5-year survival is approximately $62 \%$. The overall 5 year survival for recurrent disease is approximately $37 \%$. Because of the risk of recurrence, all patients who have had a histologically proven malignant salivary gland tumour should have lifelong follow-up.7,8

\section{CONCLUSION}

Salivary duct carcinoma is characterized by aggressive growth, a high incidence of early lymph node metastasis and frequent local recurrences after surgical excision. Combined modality that includes radical surgery with neck dissection and adjuvant radiotherapy may result in the oncological cure of the disease. ${ }^{9-14}$

\section{REFERENCES}

1. Kleinsasser O, Klein HJ, Hubner G. Salivary duct carcinoma. A group of salivary gland tumours analogous to mammary duct carcinoma. Arch Klin Exp Ohren Nasen Kehlkopfheilkd 1968;192(1):100-5.

2. Simpson RH, Robertson NJ, Aroa DS, et al. Salivary duct carcinoma: a cytological and histological study. Cytopathology 1996;7(2):141-4.

3. Lewis JE, Olsen KD, Sebo TJ. Carcinoma ex-pleomorphic adenoma: pathologic analysis of 73 cases. Hum Pathol 2001;32(6):596-604.

4. Seifert G, Sobin LH, eds. Histological typing of salivary gland tumours. WHO International Histological Classification of Tumours. $2^{\text {nd }}$ ed. New York: SpringerVerlag Publishers 1991.

5. Gal R, Strauss M, Zohar Y, et al. Salivary duct carcinoma of the parotid gland. Cytologic and histopathologic study. Acta Cytol 1985;29(3):454-6.

6. Delgado R, Vuitch F, Albert-Saavedra J. Salivary duct carcinoma. Cancer 1993;72:1503-12.

7. Jamal AM, Sun ZJ, Chen XM, et al. Salivary duct carcinoma of the parotid gland: case report and review of the literature. J Oral Maxillofac Surg 2008;66(8):1708-13.

8. Nagao T, Gaffey TA, Serizawa H, et al. Sarcomatoid variant of salivary duct carcinoma: clinicopathologic and immunohistochemical study of eight cases with review of the literature. Am J Clin Pathol 2004;122(2):222-31.

9. Butterworth DM, Jones AW, Kotecha B. Salivary duct carcinoma: report of a case and review of the literature. Virchows Arch A Pathol Anat Histopathol 1992;420(4):371-4.

10. Minamiguchi S, Iwasa Y, Shoji K, et al. Salivary duct carcinoma: a clinicopathologic study of three cases with a review of the literature. Pathol Int 1996;46(8):614-22.

11. Kruslin B, Scukanec-Spoljar M, Separovic V, et al. Salivary duct carcinoma metastasizing to the small bowel. Tumori 1996;82(5):502-4.

12. Ikeda K, Yoshida F, Suzuki H, et al. A case report of salivary duct carcinoma. Tohoku J Exp Med 1997;183(3):233-8.

13. Madrigal B, García J, De Vicente JC. Salivary duct carcinoma: an unusual case of long-term evolution. Oral Surg Oral Med Oral Pathol Oral Radiol Endod 1999;88(5):597-602.

14. Bhalla R, Parker DC, Tadros TS. Salivary duct carcinoma metastatic to inguinal lymph node: a case report of salivary duct carcinoma with distant metastasis diagnosed by fine-needle aspiration. Diagn Cytopathol 2006;34(1):41-4. 